\title{
Study of growth and yield of winter wheat using WOFOST model based on wireless sensor network data
}

\author{
Wu Huarui ${ }^{* 1,2,3, a}$, Zhu Huaji, 2,3, b , Zhang Lihong $^{1,2,3, \mathrm{c}}$, and Miao Yisheng ${ }^{1,2,3, \mathrm{~d}}$ \\ ${ }^{1}$ National Engineering Research Center for Information Technology in Agriculture, Beijing 100097, \\ PR China \\ ${ }^{2}$ Beijing Research Center for Information Technology in Agriculture, Beijing Academy of Agriculture \\ and Forestry Sciences, Beijing 100097, PR China \\ ${ }^{3}$ Key Laboratory for Information Technologies in Agriculture, Ministry of Agriculture, Beijing 100097, \\ PR China \\ awuhrnercita@163.com, bzhuhj@nercita.org.cn, 'zhanglh@nercita.org.cn, 'miaoys@nercita.org.cn \\ *Corresponding author: Tel:+86-10-51502031; Fax: +86-10-51503750 \\ E-mail: wuhrnercita@163.com
}

Address: Room 702, Building A, Beijing Nongke Masion, 11\#Shuguang Huayuan Middle Road, Haidian District, Beijing, China, 100097

Keywords: Winter wheat, WOFOST model, simulation, yield, WSN

\begin{abstract}
This study aims to research the applicability of the WOFOST model and predict winter wheat yield on a regional scale. The automatic information in study area could be achieved from the wireless sensor network (WSN) deployed in cropland. The observed results including the phenological dates, LAI and the yield are compared with the simulated results in WOFOST. It is found that the maximum deviation of observed and simulated days taken to anthesis is seven days, and the maximum deviation of observed and simulated days taken to maturity is five days. The simulated days to anthesis and days to maturity indicate that WOFOST model underestimates the phenological period of wheat in both years. Through the analysis of LAI, it can be seen that simulated results are agree well with the observed results, except the early stage of growth. The phenomenon can be attributed to the simulated growth period is earlier than the actual test. Moreover, the observed mean yields are 5410 and $5536 \mathrm{~kg} \mathrm{ha}^{-1}$ during 2006-2007 and 2007-2008, respectively. The simulated mean yields are 5936 and $6027 \mathrm{~kg} \mathrm{ha}^{-1}$ during 2006-2007 and 2007-2008, respectively. Based on the relative root mean square error, the modified WOFOST model presented a very good to fair estimation of wheat yields. The results of this study provide an important theoretical reference for WOFOST model monitoring and estimating winter wheat growth status on a regional scale. It indicates that WOFOST model is a useful tool in yield forecasting.
\end{abstract}

\section{Introduction}

With the growing of population and reducing of cropland, we are facing more and more serious food security issues. Accurate monitoring of crop growth and prediction of yield are crucial for agricultural management [1]. In the field experiment, taking into account all influencing factors is not realistic because the process is evidently time consuming and expensive [2]. Therefore, development or even validation of simulation model could be the best alternative to study production constraints of crops.

In recent years, many models have been developed to evaluate crops yield and their growth under different environmental conditions, management practices and considering effects of many variables on crops, such as EPIC, WOFOST, DSSAT, and AquaCrop [3]. Based on system analysis and computer simulation techniques, crop growth models can dynamically describe the fundamental processes such as photosynthesis, respiration, biomass partitioning and soil water balance [4]. The crop growth simulation model WOFOST is a member of family of Wageningen crop models [2]. It is 
a mechanistic process-based model which applies generic process description assuming that weather, soil and crop data are homogeneous [5]. Specifically, the growth-driving processes describe the plant growth based on light interception and $\mathrm{CO}_{2}$ assimilation; the growth-controlling processes describe the crop phenological development [6]. According to the dimensionless variables, the crop development stages can be divided into three stages, i.e. zero representing emergence, one representing anthesis, and two representing maturity. Moreover, the WOFOST model can be applied in two modes: the potential mode, in which crop growth is determined by temperature, day length, solar radiation and genetic characteristics assuming absence of any water or other stress factors; the water-limited mode, in which crop growth is influenced by rainfall, soil type and field topography. In both modes, we assume that the nutrient supply is optimal, and other yield-limiting factors such as pests, weeds, and farm management are not considered [7]. LAI is one of the most important state variables in the WOFOST model, and it can indicate the potential grain yield. Moreover, LAI can indicate the ability of the crop to intercept solar radiation, which drives $\mathrm{CO}_{2}$ assimilation [8]. Supit et al. $[9,10]$ studied the main annual crops over Europe under present and future conditions through WOFOST model. Reidsma et al. [11] researched its application in regional land evaluation, yield potential, risk analysis and yield forecasting in Europe and Africa. Moreover, Wolf et al. [12] have validated the modeling results from WOFOST versus experimental information by way of model comparison exercises.

The traditional planting pattern in the North China Plain is a winter wheat-summer maize rotation. China is considered to be one of the world's largest food producer, and winter wheat comprises about $85 \%$ of China's total summer grain production. Hence, accurate regional monitoring of wheat growth and yield prediction have become crucial for national food security and sustainable agricultural development. The aim of this modeling study is to assess winter wheat growth and yield in regional area in China using the WOFOST model. In recent years, wireless sensor networks (WSNs) has become a research topics [13]. WSN is comprised of numbers of sensor nodes which are capable of sensing, processing, and transmitting environmental information [14]. The automatic information in study area could be achieved from the wireless sensor nodes deployed in cropland.

\section{Materials and Methods}

\section{Study area and field data collection}

The study was conducted in xiaotangshan national precision agriculture research demonstration base. The study area has a size of $1.65 \mathrm{hm}^{2}$, and is dominated by winter wheat cultivation with an average temperature of $12^{\circ} \mathrm{C}$. W inter wheat is generally planted at the beginning of September and harvested in June of the next year. The important phenological stages for winter wheat include the green-up stage, jointing stage, elongation stage, booting stage, heading stage, anthesis stage, and maturity stage. The daily weather data were recorded at agrometeorological observatory. The soil samples were collected and analyzed from the wireless sensor nodes deployed in cropland.

\section{Evaluation of the results}

To evaluate the difference between the simulated and measured values, the root mean square error (RMSE) and relative root mean square error (PRMSE) can be calculated as follows:

$$
\begin{aligned}
& \text { RMSE }=\sqrt{\frac{\sum_{i=1}^{N}\left(S_{i}-M_{i}\right)^{2}}{N} .} \\
& \text { PRMSE }=\frac{R M S E}{M_{i}} \times 100 \% .
\end{aligned}
$$

where $\mathrm{M}_{\mathrm{i}}, \mathrm{S}_{\mathrm{i}}, \mathrm{N}$, and $\overline{\mathrm{M}_{\mathrm{i}}}$ are the measured value, the simulated value, the number of samples, and the average measured value, respectively. The value of RRMSE varies from 0 to 1 . The value of RRMSE is more closer to 0, the model is more accurate. As proposed by Jamieson et al. [15], prediction was considered excellent when the RRMSE $<10 \%$, good if $10-20 \%$, fair if $20-30 \%$ and poor if $>30 \%$. 


\section{Results and discussions \\ Days taken to anthesis}

To accurate simulate the crop growth and yield, the evaluation of the phasic development is the first step which assessing the performance of a simulation crop model. As shown in Table 1, the observed and simulated days to anthesis for 2006-9 and 2007-9 are 227 and 225, respectively. Through the analysis of deviation, we find that the model performed better during 2007-2008 than 2006-2007. It can be seen that the WOFOST model underestimates the days to anthesis for wheat in both years.

\section{Days taken to maturity}

The simulated days to maturity are 258 and 267 for 2006-9 and 2007-9, respectively. The observed days to maturity are 263 and 269 for 2006-9 and 2007-9, respectively. Similarly, the WOFOST model underestimates the days to maturity for wheat in both years. Moreover, the performance of WOFOST model in terms of simulated days to maturity is found superior during 2007-2008 than that in 2006-2007.

Table 1. The comparison of simulated and observed growth period dates.

\begin{tabular}{|c|c|c|c|c|c|c|c|}
\hline \multirow[t]{2}{*}{ Year } & \multirow{2}{*}{$\begin{array}{l}\text { Sowing } \\
\text { date }\end{array}$} & \multicolumn{2}{|c|}{$\begin{array}{l}\text { Days taken to anthesis } \\
\text { (d) }\end{array}$} & \multirow[t]{2}{*}{ Error (d) } & \multicolumn{2}{|c|}{$\begin{array}{l}\text { Days taken to maturity } \\
\text { (d) }\end{array}$} & \multirow[t]{2}{*}{ Error (d) } \\
\hline & & $\begin{array}{l}\text { Simulated } \\
\text { value }\end{array}$ & $\begin{array}{l}\text { Observed } \\
\text { value }\end{array}$ & & $\begin{array}{l}\text { Simulated } \\
\text { value }\end{array}$ & $\begin{array}{l}\text { Observed } \\
\text { value }\end{array}$ & \\
\hline $\begin{array}{c}2006-200 \\
7\end{array}$ & $9-27$ & 227 & 234 & 7 & 258 & 263 & 5 \\
\hline $\begin{array}{c}2007-200 \\
8 \\
\end{array}$ & $9-29$ & 225 & 228 & 3 & 267 & 269 & 2 \\
\hline
\end{tabular}

\section{Maximum leaf area index (LAI)}

The relationship between measured and simulated leaf area index during 2006-2008 are shown in Fig. 1. Through the analysis of LAI for winter wheat during 2006-2008, we find that the simulated results are agree well with the observed results, except the early stage of growth. The phenomenon can be attributed to the simulated growth period is earlier than the actual test. The correlation coefficient is 0.93 during 2006-2007, and 0.92 in 2007-2008. The values of RMSE for simulated maximum LAI are 0.11 and 0.08 for 2006-2007 and 2007-2008, respectively. 

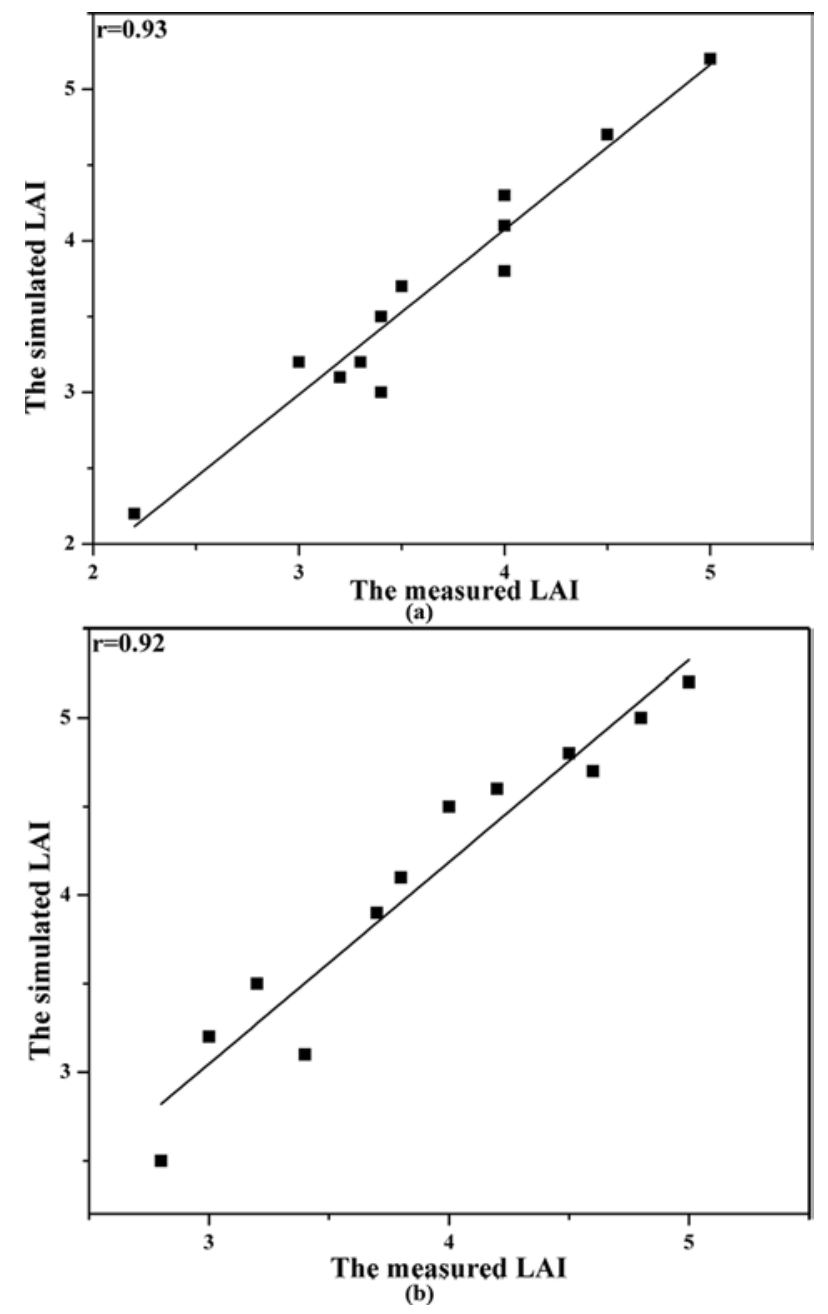

Fig. 1. The simulated and measured LAI under different dates of sowing. (a) 2006-2007 (b) 2007-2008.

\section{Grain yield}

From Fig. 2, it can be found that the observed mean yields are 5410 and $5536 \mathrm{~kg} \mathrm{ha}^{-1}$ during 2006-2007 and 2007-2008, respectively. The simulated mean yields are 5936 and $6027 \mathrm{~kg} \mathrm{ha}^{-1} \mathrm{during}^{-1}$ 2006-2007 and 2007-2008, respectively. The RMSE during 2007-2008 is lower than that during 2006-2007. Likewise, the correlation coefficients during 2006-2007 and 2007-2008 are 0.83 and 0.89, respectively. WOFOST is a mechanistic crop growth simulation model that can capture the complex effect of climate, genotype and agronomic variable through several functions. Perhaps, such a variation could be intrinsic to the model. For example, Seino et al. [16] found a similar result through comparing the simulated and observed yield of wheat crop. 

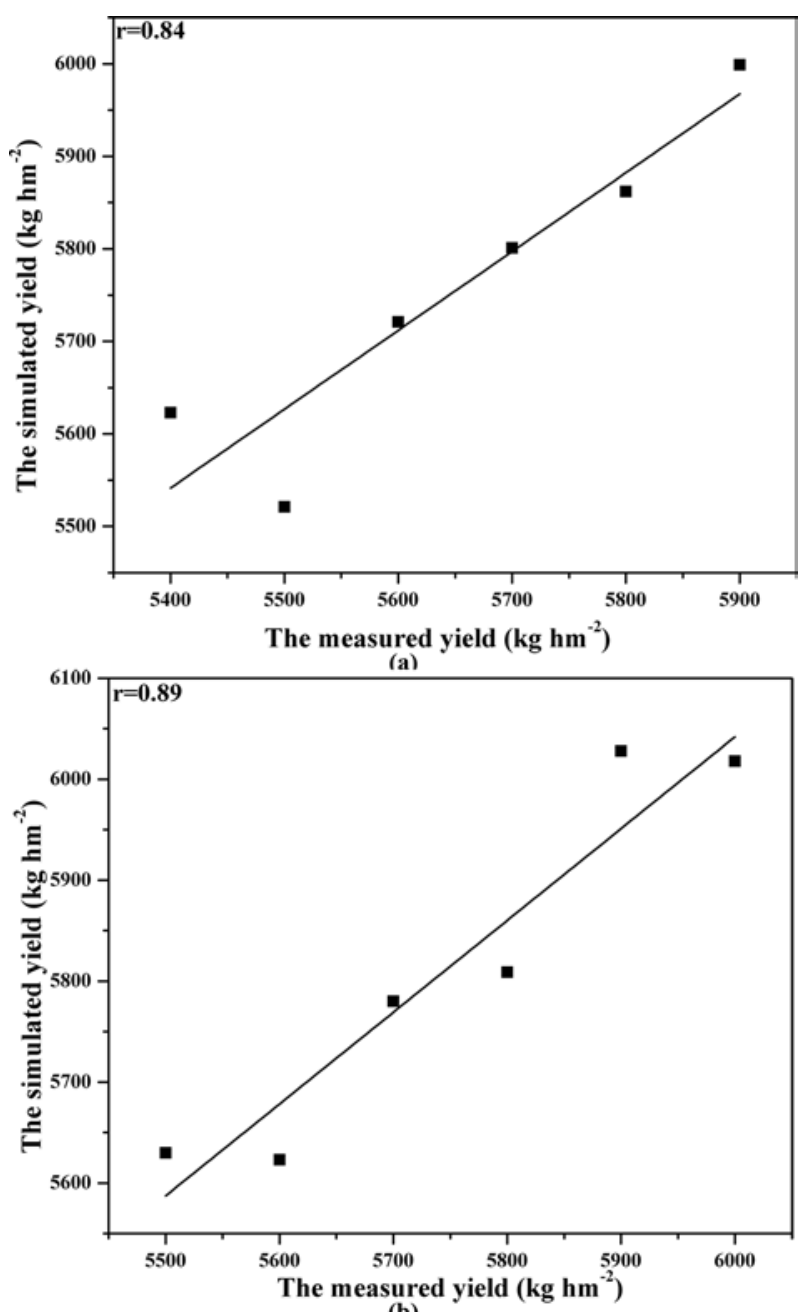

Fig. 2. The simulated and measured yield under different dates of sowing (a) 2006-2007 (b) 2007-2008.

\section{Conclusions}

The anthesis date, days to maturity, the maximum leaf area index, the grain yield are simulated by the WOFOST model of wheat sown under different environmental conditions. It is found that the maximum deviation of observed and simulated days taken to anthesis was seven days, and the maximum deviation of observed and simulated days taken to maturity was five days. The simulated days to anthesis and days to maturity indicate that WOFOST model underestimates the phenological period for wheat in both years. Through the analysis of LAI, it can be seen that simulated results are agree well with the observed results, except the early stage of growth. The phenomenon can be attributed to the simulated growth period is earlier than the actual test. Moreover, the observed mean yields are 5410 and $5536 \mathrm{~kg} \mathrm{ha}^{-1}$ during 2006-2007 and 2007-2008, respectively. The simulated mean yields are 5936 and $6027 \mathrm{~kg} \mathrm{ha}^{-1}$ during 2006-2007 and 2007-2008, respectively. This clearly shows the robustness of the WOFOST model for growth and yield simulation of wheat crop. The results of this study provide an important theoretical reference for WOFOST model monitoring and estimating winter wheat growth status on a regional scale. It indicates that WOFOST model is a useful tool in yield forecasting.

\section{Acknowledgments}

This work is supported by Natural Science Foundation of China $(61271257,61471067,61571051)$. 


\section{References}

[1] J. Huang, F. Sedano, Y. Huang, H. Ma, X. Li, S. Liang, L. Tian, X. Zhang, J. Fan, W. Wu, Assimilating a synthetic Kalman filter leaf area index series into the WOFOST model to improve regional winter wheat yield estimation, Agricultural \& Forest Meteorology, 216 (2016) 188-202.

[2] S. Mishra, A. Shekh, S. Yadav, A. Kumar, G. Patel, V. Pandey, H. Patel, Simulation of growth and yield of four wheat cultivars using WOFOST model under middle Gujarat region, Journal of Agrometeorology, 15 (2013) 43.

[3] N. Yarami, A. Sepaskhah, Modification of the saffron model for growth and yield prediction under different irrigation water salinity, manure application and planting methods, International Journal of Plant Production, 10 (2016).

[4] Ma G, Huang J, Wu W, et al. Assimilation of MODIS-LAI into the WOFOST model for forecasting regional winter wheat yield[J]. Mathematical and Computer Modelling, 2013, 58(3): 634-643.

[5] L.G.J.V. Bussel, F. Ewert, G. Zhao, H. Hoffmann, A. Enders, D. Wallach, S. Asseng, G.A. Baigorria, B. Basso, C. Biernath, Spatial sampling of weather data for regional crop yield simulations, Agricultural \& Forest Meteorology, 220 (2016) 101-115.

[6] J. Huang, L. Tian, S. Liang, H. Ma, I. Becker-Reshef, Y. Huang, W. Su, X. Zhang, D. Zhu, W. Wu, Improving winter wheat yield estimation by assimilation of the leaf area index from Landsat TM and MODIS data into the WOFOST model, Agricultural \& Forest Meteorology, 204 (2015) 106-121.

[7] L.G.J.V. Bussel, F. Ewert, G. Zhao, H. Hoffmann, A. Enders, D. Wallach, S. Asseng, G.A. Baigorria, B. Basso, C. Biernath, Spatial sampling of weather data for regional crop yield simulations, Agricultural \& Forest Meteorology, 220 (2016) 101-115.

[8] J. Huang, F. Sedano, Y. Huang, H. Ma, X. Li, S. Liang, L. Tian, X. Zhang, J. Fan, W. Wu, Assimilating a synthetic Kalman filter leaf area index series into the WOFOST model to improve regional winter wheat yield estimation, Agricultural \& Forest Meteorology, 216 (2016) 188-202.

[9] I. Supit, C.A.V. Diepen, A.J.W.D. Wit, J. Wolf, P. Kabat, B. Baruth, F. Ludwig, Assessing climate change effects on European crop yields using the Crop Growth Monitoring System and a weather generator, Agricultural \& Forest Meteorology, 164 (2012) 96-111.

[10] I. Supit, C.A.V. Diepen, A.J.W.D. Wit, J. Wolf, P. Kabat, B. Baruth, F. Ludwig, Assessing climate change effects on European crop yields using the Crop Growth Monitoring System and a weather generator, Agricultural \& Forest Meteorology, 164 (2012) 96-111.

[11] I. Supit, C.A.V. Diepen, A.J.W.D. Wit, J. Wolf, P. Kabat, B. Baruth, F. Ludwig, Assessing climate change effects on European crop yields using the Crop Growth Monitoring System and a weather generator, Agricultural \& Forest Meteorology, 164 (2012) 96-111.

[12] Boon-Prins E R. Crop-specific simulation parameters for yield forecasting across the European Community[J]. 1993.

[13] Lajara R J, Perez-Solano J J, Pelegri-Sebastia J. A method for modeling the battery state of charge in wireless sensor networks[J]. IEEE Sensors Journal, 2015, 15(2): 1186-1197.

[14] An W, Ci S, Luo H, et al. Effective sensor deployment based on field information coverage in precision agriculture[J]. Wireless Communications and Mobile Computing, 2015, 15(12): 1606-1620.

[16] Jamieson P D, Porter J R, Wilson D R. A test of the computer simulation model ARCWHEAT1 on wheat crops grown in New Zealand[J]. Field crops research, 1991, 27(4): 337-350. 
[17] An W, Ci S, Luo H, et al. Effective sensor deployment based on field information coverage in precision agriculture[J]. Wireless Communications and Mobile Computing, 2015, 15(12): 1606-1620. 